\title{
Actual Versus Ideal Body Weight: The Devil Is in the Details
}

Respiratory failure remains one of the most common reasons for children to be admitted to the ICU, and a large number of these patients require invasive mechanical ventilation and progress to ARDS. Mortality related to ARDS correlates directly with the severity of lung disease, and patients who survive ARDS experience notable and longlasting morbidity. The largest breakthrough in the treatment of ARDS came in 2000, when the ARDSnet (ARDS Network) researchers published their randomized trial of $6 \mathrm{~mL} / \mathrm{kg}$ (predicted body weight) tidal volume compared with the standard care at the time for adult subjects with ARDS on mechanical ventilation of $12 \mathrm{~mL} / \mathrm{kg}$ of tidal volume. ${ }^{1}$ This study demonstrated a profound mortality benefit for the $6-\mathrm{mL} / \mathrm{kg}$ tidal volume cohort (31\% vs $40 \%$ mortality, $P=.007$ ), and these results changed our approach to treating patients with ARDS. ${ }^{1}$ Since that time, ARDS management has focused on lung-protective measures rather than short-term oxygenation and ventilation goals.

Based on the best available evidence in children and adults, the 2015 Consensus Guidelines for Pediatric Acute Respiratory Distress Syndrome ${ }^{2}$ recommend tidal volumes in or below the range of physiologic tidal volumes for age/body weight (ie, $5-8 \mathrm{~mL} / \mathrm{kg}$ predicted body weight) for children on mechanical ventilation. Note that the investigators specified predicted body weight, just as was used in the ARDSnet study ${ }^{1}$ because the patient's lung capacity is primarily determined by his or her age and height rather than by his or her current weight. Given the need to optimize lung-protective ventilation in our patients with ARDS, it is essential that we provide the appropriate tidal volume.

In this edition of Respiratory CARE, Biharz et al ${ }^{3}$ presented their study, which details differences between actual body weight and calculated ideal body weight in children receiving mechanical ventilation. By using 3 different methods to calculate ideal body weight, the investigators demonstrated that more than half of the subjects had clinically important differences between their actual and ideal

\footnotetext{
The authors have disclosed no conflicts of interest.
}

Correspondence: Kyle J Rehder MD, Division of Pediatric Critical Care Medicine, Department of Pediatrics, Duke Children's Hospital, DUMC Box 3046, Durham, NC 27710. E-mail: kyle.rehder@duke.edu.

DOI: $10.4187 /$ respcare.06534 weight, and all 3 methods for calculating ideal body weight produced similar differences. ${ }^{3}$ Of greatest concern was that the difference between ideal and actual body weight was more disparate in subjects who were heavier. In the

See the Original Study on Page 1079

subjects who were heavier, this difference between ideal and actual body weight was of even more importance given the potential implications on tidal volume. We are currently in the midst of a well-documented national and worldwide obesity epidemic, with dramatic increases in childhood obesity over the past 2 decades. ${ }^{4,5}$ In cases of patients who are severely overweight and obese, using the increased actual weight to calculate tidal volume targets will overestimate the target tidal volume and expose these patients to harmful volutrauma and barotrauma. This exposure works directly against the lung-protective strategies that have been proven to improve mortality in patients with ARDS.

Although obesity rates have stabilized in adults, they continue to increase in children. ${ }^{5}$ We can expect to continue to see increasing numbers of children who are overweight and obese who present with respiratory failure and require invasive mechanical ventilation. Therefore, it is imperative that we are using appropriate tidal volume targets. Biharz et $\mathrm{al}^{3}$ clearly demonstrated that, if we rely on measured body weight, then we will be deviating from ideal targets in the majority of our patients, which puts many patients at unnecessary risk. Furthermore, patients who are obese will typically have lower baseline tidal volumes, along with reduced chest wall compliance due to the weight of their soft tissues. ${ }^{6}$ This reduced compliance will only result in a higher driving pressure required to reach any calculated super-physiologic tidal volume. These same patients who are obese will be at greater baseline risk of progressing to ARDS due to elevated levels of circulating inflammatory cytokines and increased areas of atelectasis, which are susceptible to atelectotrauma from shear stress during opening and closing of the alveoli. ${ }^{7}$ Analysis of the limited data indicates that targeting lower tidal volumes, paired with an open lung strategy, may be even more beneficial in patients who are obese than in patients who are normal weight. ${ }^{6}$

Using the correct weight to accurately define tidal volume targets is important; however, it is only the first step 


\section{EDITORIALS}

in ensuring that we provide optimal lung-protective ventilation to our pediatric patients. Many factors contribute to our ventilator management and our patients' ability to recover from their illness. Accurately measuring delivered tidal volume at the endotracheal tube rather than at the ventilator $^{8}$; titrating PEEP to optimal lung expansion; monitoring changing lung mechanics; and carefully managing other nonpulmonary issues to avoid complications, such as fluid overload, delirium, and hospital-acquired infections, all play a significant role in ensuring the best possible outcomes in our pediatric patients with respiratory failure. ${ }^{2}$

Kyle J Rehder MD David A Turner MD Division of Pediatric Critical Care Medicine Department of Pediatrics Duke Children's Hospital Durham, North Carolina

\section{REFERENCES}

1. Acute Respiratory Distress Syndrome Network, Brower RG, Matthay MA, Morris A, Schoenfeld D, Thompson BT, Wheeler A. Ventilation with lower tidal volumes as compared with traditional tidal volumes for acute lung injury and the acute respiratory distress syndrome. The Acute Respiratory Distress Syndrome Network. N Engl J Med 2000; 342(18):1301-1308.

2. Pediatric Acute Lung Injury Consensus Conference Group. Pediatric acute respiratory distress syndrome: consensus recommendations from the Pediatric Acute Lung Injury Consensus Conference. Pediatr Crit Care Med 2015;16(5):428-439.

3. Biharz. A comparative analysis of ideal body weight methods for pediatric mechanical ventilation. Respir Care 2018.

4. GBD 2015 Obesity Collaborators, Afshin A, Forouzanfar MH, Reitsma MB, Sur P, Estep K, Lee A, et al. Health Effects of Overweight and Obesity in 195 Countries over 25 Years. N Engl J Med 2017; 377(1):13-27.

5. Skinner AC, Ravanbakht SN, Skelton JA, Perrin EM, Armstrong SC. Prevalence of Obesity and Severe Obesity in US Children, 1999-2016. Pediatrics 2018. [Epub ahead of print] doi: 10.1542/peds.2017-3459.

6. Leme Silva P, Pelosi P, Rocco PR. Mechanical ventilation in obese patients. Minerva Anestesiol 2012;78(10):1136-1145.

7. Hibbert K, Rice M, Malhotra A. Obesity and ARDS. Chest 2012; 142(3):785-790.

8. Emeriaud G, Newth CJ, Pediatric Acute Lung Injury Consensus Conference G. Monitoring of children with pediatric acute respiratory distress syndrome: proceedings from the Pediatric Acute Lung Injury Consensus Conference. Pediatr Crit Care Med 2015;16(5 Suppl 1): S86-S101. 